\title{
O trabalho dos Agentes Comunitários de Saúde à luz da Teoria Comunidades de Prática
}

\author{
The work of Community Health Workers \\ in light of Communities of Practice Theory
}

\author{
Raquel de Castro Alves Nepomuceno (https://orcid.org/0000-0003-3121-8814) ${ }^{1}$ \\ Ivana Cristina de Holanda Cunha Barreto (https://orcid.org/0000-0001-8447-3654) ${ }^{2}$ \\ Amanda Cavalcante Frota (https://orcid.org/0000-0003-3944-2263) ${ }^{2}$ \\ Kelen Gomes Ribeiro (https://orcid.org/0000-0003-0870-1971) ${ }^{3}$ \\ Ana Ecilda Lima Ellery (https://orcid.org/0000-0001-8350-464X) ${ }^{4}$ \\ Francisco Antonio Loiola (https://orcid.org/0000-0003-3720-2936) ${ }^{5}$ \\ Luiz Odorico Monteiro de Andrade (https://orcid.org/0000-0002-3335-0619) ${ }^{2}$
}

\footnotetext{
${ }^{1}$ Secretaria Municipal de Saúde de Fortaleza. R. Barão do Rio Branco 910, Centro. 60310-330 Fortaleza CE Brasil.nepomuceno.raquel@ gmail.com

${ }^{2}$ Fundação Oswaldo Cruz Ceará (Fiocruz Ceará). Eusébio CE Brasil. ${ }^{3}$ Faculdade de Medicina, Universidade Federal do Ceará. Fortaleza CE Brasil. ${ }^{4}$ Grupo de Pesquisa Essência, Fiocruz Ceará. Fortaleza CE Brasil.

${ }^{5}$ Département de psychopédagogie et d'andragogie Université de Montréal.

Montreal QC Canada.
}

\begin{abstract}
The work of Community Health Workers (ACS) was analyzed in light of Communities of Practice (CP) theory. This is a qualitative crosssectional study carried out in four municipalities in Ceará. Six focus groups and six interviews were carried out with 45 Community Health Workers (ACS), observing ethical aspects. The data corpus was analyzed using the content analysis technique. The results show that ACS participation in the ESF is marked by experience in the community, and the main focus is monitoring priority groups. The practices put them before the diverse social and family complexities, generating reflections and building new meanings for themselves and their work process. The ACS CPs engage and share challenges and unique learning from work, characterized by close contact and relationships with the families of the territory, which reveals needs hardly perceived by other ESF professionals. The meaning of being ACS as one who listens, embraces, and perceives the needs of families invisible to services, is evident in the reification processes. The ACS better exercise their role as ESF articulators in the territories the greater the spaces for dialogue between them, the other team members, and management.
\end{abstract}

Key words Community Health Worker, Family Health Strategy, Practice Communities, Primary Health Care
Resumo Analisou-se o trabalho dos Agentes Comunitários de Saúde (ACS), à luz da teoria das Comunidades de Prática (CdP). Estudo qualitativo transversal, realizado em quatro municípios do Ceará. Realizaram-se seis grupos focais e seis entrevistas com 45 ACS, respeitando os aspectos éticos. O corpus de dados foi analisado pela técnica de análise de conteúdo. Os resultados apontaram que a participação dos ACS na ESF é marcada pela vivência na comunidade, sendo o foco principal o acompanhamento dos grupos prioritários. As práticas os colocam diante das diversas complexidades sociais e familiares, gerando reflexões e construções de novos significados para si e o processo de trabalho. As CdP dos ACS se engajam e compartilham desafios e aprendizados singulares do trabalho, caracterizado pelo contato e relacionamento intimo com as famílias do território, que revelam necessidades pouco percebidas pelos demais profissionais da ESF. Quanto aos processos de reificação, evidenciou-se o significado de ser ACS como aquele que escuta e acolhe, além do que, percebe as necessidades das famílias invisiveis aos serviços. Os ACS exercem melhor o papel de articulador da ESF nos territórios, quanto maior forem os espaços de diálogo entre eles, os demais membros da equipe e a gestão.

Palavras-chave Agentes Comunitários de Saúde, Estratégia Saúde da Família, Comunidades de Prática, Atenção Primária à Saúde 


\section{Introdução}

Os Agentes Comunitários de Saúde (ACS) são considerados trabalhadores estratégicos para o principal modelo de operacionalização da Política Nacional de Atenção Básica (PNAB) do Brasil - a Estratégia Saúde da Família (ESF) - e constituem categoria profissional relativamente nova, reconhecida pela Lei ${ }^{\circ} 10.507 / 2002^{1}$. Apesar de nova, a categoria tem largo percurso de existência como função ou ocupação, desde a instituição no Sistema Único de Saúde (SUS), no Programa de Agentes Comunitários de Saúde (PACS), que foi implantado, inicialmente, nas regiões Norte e Nordeste, em 1991². Diante da incipiente cobertura médico-sanitária nestas regiões, os agentes foram gradualmente capacitados para diversas atribuições, como cadastramento da população, diagnóstico comunitário, identificação de áreas de risco e promoção das ações de proteção à saúde da criança e da mulher com prioridade, em face da vulnerabilidade desses grupos ${ }^{3}$.

O PACS foi considerado uma estratégia transitória para a ESF, que visa reorientação do modelo assistencial, substituindo o modelo tradicional, hospitalocêntrico, de assistência orientada para a cura de doenças, para um modelo cujas principais características são o enfoque sobre a família, com vistas à promoção da saúde ${ }^{4}$. Diversos problemas sociais e de saúde foram sendo adicionados às responsabilidades da ESF e, em especial, aos ACS, como o acompanhamento das condicionalidades do Programa Bolsa Família, acompanhamento às pessoas com doenças crônicas, acamados, prevenção à infestação dos domicílios pelos Aedes aegypti, ações de prevenção à dependência de drogas, entre outros ${ }^{5}$.

Estudos apontam problemas relacionados ao trabalho desses profissionais, como carência de limites das atribuições ${ }^{6,7}$; precárias condições de trabalho ${ }^{6-9}$; a exposição à violência ${ }^{10,11}$; escassez de articulação com os demais membros da equipe multiprofissional ${ }^{12,13}$; maior prevalência de depressão $0^{14}$, dentre outros. A discussão sobre a prática desses profissionais, no decorrer desta trajetória, tem crescido com as propostas políticas de organização do Sistema Único de Saúde (SUS) ${ }^{15-17}$. Em 2017, aprovou-se revisão da PNAB, que estabeleceu mudanças na organização da atenção básica envolvendo diretamente os ACS. Criou-se a possibilidade de nova modalidade de equipe "Atenção Básica", composta minimamente por médico, enfermeiro, auxiliares e/ ou técnicos de enfermagem, sem a obrigação do ACS na equipe. A PNAB 2017 acrescentou novas atribuições para o ACS, dentre elas, aferir a pressão arterial, realizar a medição da glicemia capilar e proceder às técnicas limpas de curativos, inclusive, em domicílio ${ }^{17}$.

Como categoria nova no Brasil e em processo de fortalecimento e desenvolvimento da identidade profissional, instiga-se pensar de que forma os ACS vão constituindo e consolidando as práticas de trabalho. Existe contradição entre o processo de formação que os ACS recebem para atuar e o que executam, sendo o primeiro avaliado como insuficiente ${ }^{18}$. Mesmo assim, os ACS coletivamente conseguem apresentar bons resultados no trabalho, suscitando o questionamento sobre como aprendem a realizar as atribuições profissionais.

A Teoria das Comunidades de Práticas $(\mathrm{CdP})^{19}$ busca compreender justamente o aprendizado que ocorre no cotidiano dos grupos sociais, como as pessoas se engajam umas com as outras e ao compromisso entre estas, por meio de interesses compartilhados, como resolvem os problemas e como isso vai se tornando um aprendizado. Assim, este estudo buscou analisar o trabalho dos Agentes Comunitários de Saúde, à luz das CdP, com enfoque nos elementos constituintes, bem como na participação e negociação de significados.

\section{Métodos}

Componente da pesquisa intitulada "Campo de Práticas Profissionais e Acesso ao Cuidado na Estratégia Saúde da Família (ESF) do Ceará", que investigou a ESF, a partir do campo de práticas da equipe de referência e de cada categoria profissional que a compõe, relacionando este conjunto de práticas ao acesso à atenção à saúde pela população ${ }^{5}$, este estudo é um recorte qualitativo e transversal sobre ator específico da equipe, o Agente Comunitário de Saúde (ACS), inserindose no campo da investigação qualitativa.

A pesquisa qualitativa começa com pressupostos e uso de estruturas interpretativas/teóricas que informam o estudo dos problemas da pesquisa, abordando os significados que os indivíduos ou grupos atribuem a um problema social ou humano ${ }^{20}$.

Selecionaram-se quatro municípios do Ceará como locais do estudo: Fortaleza, Eusébio, Tauá e Cruz. Os municípios são de distintos portes e regiões do Estado, em virtude da esperada variabilidade do campo de práticas profissionais da ESF, encontrada em distintos contextos, ou seja, 
municípios com tamanho populacional, características socioambientais, desenvolvimento econômico e rede de serviços de saúde diferentes. No caso da capital, em virtude da extensão e grande quantidade de profissionais de saúde na ESF, o que elevaria muito os custos e o tempo para realização do estudo, definiu-se a inclusão da regional II, delimitada geograficamente, a qual possui doze centros de saúde da família. Os municípios incluídos possuíam serviços de atenção primária à saúde avaliados pelo Programa de Melhoria do Acesso e da Qualidade da Atenção Básica (PMA$\mathrm{Q}-\mathrm{AB})^{5}$.

Participaram os profissionais da ESF de duas equipes completas em cada município, que atuavam no território por, no mínimo, seis meses e tinham número de famílias adscritas, infraestrutura e insumos adequados para funcionamento. Se várias equipes preenchessem a este critério, eram selecionadas as que possuíam maior número de ACS. Nos municípios de Tauá e Cruz, selecionaram-se uma equipe da zona rural e outra na urbana. Para construção do material empírico, utilizaram-se das técnicas de grupo focal (GF) e entrevistas (E) em profundidade. Realizaram-se seis GF, com 39 participantes e seis entrevistas individuais, totalizando 45 participantes no estudo. Os GF e as entrevistas foram orientados por roteiro de perguntas abertas e realizados de outubro de 2017 a janeiro de 2018. Dois grupos focais foram realizados em três municípios: Fortaleza, Tauá e Cruz. Em Tauá e Cruz, procederam-se ao GF na zona rural e outro, na zona urbana. Em Eusébio, efetuaram-se seis entrevistas, devido ao pequeno número de ACS por equipe, conforme Quadro 1. As entrevistas foram gravadas e transcritas na íntegra, para registro fidedigno das falas.

O corpus de dados foi interpretado, tendo como referencial teórico-metodológico as dimensões que compõem uma Comunidade de Práticas (CdP). A Teoria das CdP fundamenta-se epistemologicamente na Teoria Social da Aprendizagem de Wenger, mas vai além desta ${ }^{19}$. O foco principal da CdP está no aprendizado como resultante da participação social ${ }^{19}$. À medida em que as pessoas participam, se envolvem e se mobilizam, realizando ou elaborando projetos, trocando impressões, intenções, práticas e saberes, elas aprendem, adaptando-se uns aos outros e ao contexto. Juntas, as pessoas são motivadas a aprender e colaborar coletivamente, a negociar sentidos, a produzir práticas que evoluem e a estabelecer relações sociais ${ }^{21}$.
O poder analítico do conceito de CdP reside precisamente na integração de quatros elementos: prática, significado, comunidade e identidade. A prática é um processo pelo qual se pode experimentar o mundo e o envolvimento do sujeito com ele como significativo. O significado envolve a interação de dois processos constituintes, denominados de participação e reificação, fundamental para experiência humana de significado e, portanto, para natureza prática. Para associar prática e comunidade, a CdP descreve três dimensões fundamentais: o engajamento mútuo, um projeto comum e um repertório compartilhado. As questões de identidade são um aspecto integrante da Teoria Social de Aprendizagem e, portanto, são inseparáveis das questões de prática, comunidade e significado ${ }^{19}$.

Para o tratamento dos dados oriundos dos GF e das entrevistas, utilizou-se do método da análise de conteúdo ${ }^{22}$, seguindo os seguintes passos operacionais: ordenação, classificação e análise final das informações ${ }^{23}$. A aproximação com os significados explícitos e implícitos nestes materiais nortearam a definição dos núcleos de sentido e as duas categorias nomeadas, que foram: Participação do ACS na ESF e Processos de reificações criados pelas práticas. Desta maneira, despontaram, dessa fase, as categorias temáticas que foram aprofundadas na discussão. Os aspectos éticos foram respeitados, sendo observadas normas da Resolução 466/12, do Conselho Nacional de Saúde $(\mathrm{CNS})^{24}$. A pesquisa foi autorizada por comitê de ética.

\section{Resultados e Discussão}

A análise e discussão deste estudo se basearam na participação social dos ACS na ESF, analisando os significados que extraem da prática, bem como os processos de reificação desenvolvidos. O termo participação é utilizado para descrever a experiência social de viver no mundo, em termos de participação em comunidades sociais. É um processo complexo que combina fazer, falar, pensar, sentir e pertencer. Envolve toda a pessoa, incluindo corpos, mentes, emoções e relações sociais. Pode envolver todos os tipos de relações, tanto conflituosas como harmoniosas, íntimas e políticas, competitivas e cooperativas ${ }^{19}$.

A participação social e negociação de significados produzidos estão representados esquematicamente na Figura 1. 


\begin{tabular}{|c|c|c|c|c|c|c|}
\hline \multirow[t]{7}{*}{ 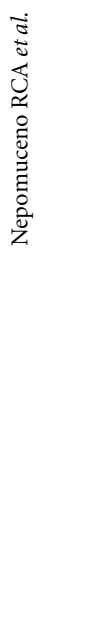 } & $\begin{array}{l}\text { Quadro 1. Detalh } \\
\text { informações. Cea }\end{array}$ & $\begin{array}{l}\text { Bento dos munic } \\
\text { Brasil, } 2018 .\end{array}$ & s, atores particip & da pesquisa & cnicas de produç & \\
\hline & Municípios & $\begin{array}{c}\text { Porte do } \\
\text { Município }\end{array}$ & Localização & $\begin{array}{l}\text { N. Grupos } \\
\text { Focais }\end{array}$ & N. Entrevistas & N. ACS \\
\hline & $\begin{array}{l}\text { Fortaleza - } \\
\text { Regional II }\end{array}$ & Grande & Capital & 2 & - & 12 \\
\hline & Tauá & Médio & $\begin{array}{l}\text { Sertões dos } \\
\text { Inhamuns }\end{array}$ & 2 & - & 14 \\
\hline & Cruz & Pequeno & Litoral Oeste & 2 & - & 13 \\
\hline & Eusébio & Médio & $\begin{array}{l}\text { Região } \\
\text { metropolitana }\end{array}$ & - & 6 & 6 \\
\hline & Total & 4 municípios & - & 6 & 6 & 45 \\
\hline
\end{tabular}

Fonte: Elaborada pelos autores.

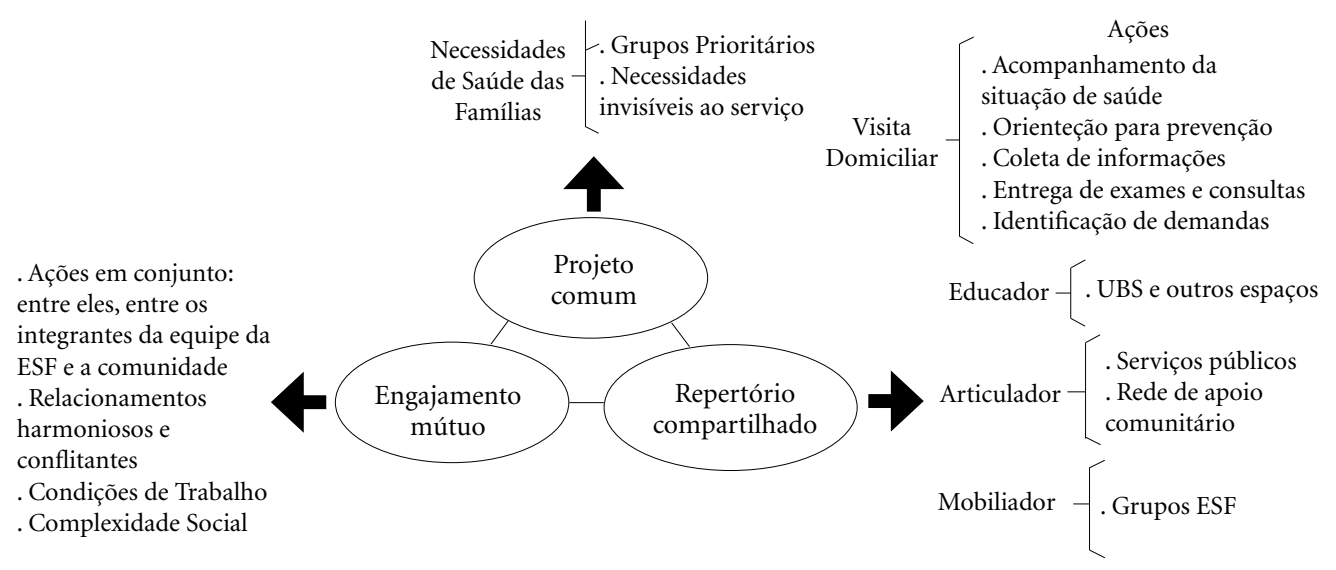

Ferramentas: fichas, fardamento, crachá,

prontuário eletrônico, aplicativo, diálogo e escuta

Figura 1. Participação social e negociação de significados produzidos pelos ACS. Ceará, Brasil, 2018.

Fonte: Adaptado de Wenger ${ }^{19}$.

\section{Pactuação de um Projeto Comum de Atuação: necessidades de saúde normativas versus necessidades de comunidades invisíveis aos serviços}

A participação dos ACS na ESF e a construção de um projeto comum de atuação são marcadas pela vivência com/na comunidade no cotidiano das práticas, principalmente por meio da visita domiciliar. $\mathrm{O}$ trabalho realizado no território compreende várias atividades, como acompanhamento da situação de saúde, orientação para prevenção, coleta de informações em saúde, entrega de exames e consultas especializadas e identificações de novas demandas, apoiando as famílias para obtenção do acesso aos serviços de saúde:

A nossa atividade diária é fazer visita domiciliares de casa em casa. Nós fazemos dez visitas por dia e vamos nas casas das gestantes, dos idosos, crianças até cinco anos de idade. Nós fazemos trabalho de peso, verificação de vacinas, informações e orientações. Também vamos à casa dos hipertensos e diabéticos (Fortaleza).

Nas visitas domiciliares, nas conversas com a familia, a gente está sempre falando dos exames 
preventivos, falando do planejamento familiar; a questão do homem ir ao médico para fazer seus exames; questão de dentistas e sempre surge alguma conversa, alguma demanda com relação aos profissionais da unidade e também sem falar nas demandas do CAPS e em relação ao tabagismo (Tauá).

Os dados apontaram que os ACS investigados tinham como projeto comum responder às necessidades de saúde demandadas pela comunidade em que atuavam. Nas visitas domiciliares, $\mathrm{o}$ foco principal de atuação é o acompanhamento dos grupos prioritários, correspondentes às ações programáticas do Ministério da Saúde: crianças menores de dois anos, gestantes, puérperas, hipertensos, diabéticos e acamados ou domiciliados. No entanto, observou-se que a realidade do cotidiano dos ACS os coloca diante de demandas das mais diversas, com situações complexas, envolvendo questões sociais e familiares, permeadas por buscas não acolhidas institucionalmente e quase sempre invisíveis aos serviços de saúde:

Função da gente é tudo na verdade: escutar de tudo. Então, não é só acompanhar um hipertenso ou um diabético ou uma gestante, a nossa função é tudo, ouvir de tudo (Eusébio).

Tem uma (usuária) que eu chego na casa dela... ela está até fazendo acompanhamento no CAPS. Ela fala que perde noite de sono, que o marido dela dorme separado dela e aquilo ali, ela fica remoendo à noite inteira. Ela disse que já deu vontade dela se matar. Aí, eu converso com ela e digo não vale a pena você fazer isso, você tem seus filhos, você tem sua vida, não vale a pena você fazer isso. Faça o seu tratamento direitinho, faça caminhada, saia para passear, saia para conversar com as amigas (Cruz).

A negociação de um projeto comum é resultado de um processo coletivo de negociação, que reflete a complexidade do engajamento mútuo, definido pelos participantes no próprio processo de construí-lo. A prática não existe no abstrato. Existe porque as pessoas estão envolvidas em ações cujos significados negociam umas com as outras $^{19}$.

No estudo, observou-se que a negociação do projeto comum não esteve apenas em objetivos declarados, como também nas atribuições especificadas destes profissionais na PNAB, ancorando na necessidade de responder às demandas de saúde das populações, produzidas por determinantes sociais da saúde ${ }^{25}$. Fator importante nessa pactuação de um projeto comum de atuação são as vulnerabilidades das famílias, aquelas que se inserem no perfil das ações programáticas e as que não. Alguns ACS tiveram dificuldade de descrever uma rotina pela imprevisibilidade das demandas que surgem no cotidiano:

Uma usuária está criando uma sobrinha, 18 anos, que está gravida e não tem marido. A filha dela foi para São Paulo e deixou uma neta de dois anos de idade, (...), que tem uma filha adolescente que está dando dor de cabeça: é junta com um homem que não dorme com ela, vive bêbado, vive brigando. (...) (Cruz).

Nossa rotina não tem como descrever. Tem dias que você pode fazer vinte visitas, mas tem dia que só dá para fazer três. E assim não posso dizer nós temos uma rotina. Não temos, porque não tem como. Eu não sei o que vai acontecer amanhã na minha área (Eusébio).

Percebeu-se a necessidade de maior acolhimento das demandas identificadas pelos ACS, tanto no sentido relacional, quanto de resolutividade e consideração da cidadania. Além das assimilações do ACS, como trabalhador, é importante que o usuário compreenda os princípios e as diretrizes do Sistema Único de Saúde, possibilitando que ele busque, de forma ativa, direitos e deveres $^{26}$, a partir de um entendimento de saúde, em uma perspectiva ampla e sistêmica.

\section{Engajamento mútuo do ACS nas práticas da equipe da ESF}

$\mathrm{O}$ interesse comum de responder às necessidades de saúde ampliadas das famílias requer o engajamento mútuo dos ACS e destes com os demais membros da equipe da ESF, nascendo, desta interação, a negociação de significados. O engajamento mútuo existe porque as pessoas estão envolvidas em ações, cujos significados elas pactuam entre si. Neste sentido, a prática não reside em livros ou ferramentas. Não reside em uma estrutura que a precede, embora não comece em um vácuo histórico. A prática reside em uma comunidade de pessoas e nas relações de engajamento mútuo, pelas quais elas podem fazer o que fizerem ${ }^{19}$.

Assim, os ACS constroem um processo de responsabilidade mútua na comunidade em que atuam, buscando vincular a população assistida à equipe da ESF como um todo, de forma a viabilizar o acesso das famílias, em especial, das mais vulneráveis, às políticas sociais e aos serviços de saúde. Desta forma, vão realizando ações em conjunto e criando relacionamentos, harmoniosos e conflituosos.

Uma das práticas, típicas em $\mathrm{CdP}$, referida repetidamente nos grupos focais, foi a inserção de novos ACS na ESF, a partir da colaboração de 
ACS mais antigos, que vão ensinando, no contexto do trabalho, as ações da profissão aos novatos. Trabalhar colaborativamente para atender a uma área que temporariamente está sem ACS, mobilizando a comunidade para ações de saneamento ambiental, coleta de lixo e eliminação de focos do mosquito Aedes aegypti, por exemplo, é um elemento do engajamento mútuo dos ACS:

Às vezes, pergunto às meninas (as colegas ACS) como é, o que está acontecendo (...). Na minha área, eu não tenho tuberculose e nem hanseníase. A gente vai nos livros ler alguma coisa e se tiver qualquer informação aquela que já tem algum problema daquele, já fala como é que você trata. (...) Então, a gente vai se ajudando dessa forma (Tauá).

Nós temos uma área descoberta na nossa equipe e a gente como ela disse sempre a gente se reúne para fazer o mutirão, vai lá e está precisando disso, ... a gente tem que fazer o mutirão e vamos sempre cobrir aquela área descoberta (Fortaleza).

Assim, quando um grupo partilha de certos interesses, de rotinas, projetos e processos de trabalho entre si, os que chegam sabem que estes elementos existem, mas precisam de tempo para se apropriarem ${ }^{27}$. Aos poucos, os recém-chegados na comunidade vão apreendendo com os demais membros as rotinas, os protocolos, os elementos reificados pela $\mathrm{CdP}$, como também contribuem no processo coletivo, com saber e experiência.

Uma prática compartilhada, portanto, conecta os participantes uns aos outros de maneiras diversas e complexas. As relações resultantes refletem a total complexidade de fazer as coisas coletivamente. $\mathrm{Na}$ vida real, as relações mútuas entre os participantes são misturas complexas de poder e dependência, prazer e dor, sucesso e fracasso, facilidade e flexibilidade, autoridade e coleguismo, resistência e conformidade, raiva e ternura, diversão e aborrecimento, confiança e suspeita, amizade e ódio. As comunidades da prática têm tudo isso ${ }^{19}$.

Dentro da multiplicidade emergente nas comunidades de práticas, os ACS vivenciam o conflito de ter de atender às exigências da gestão, como a coleta de informações detalhadas sobre as famílias, em detrimento das demandas de adoecimento que, frequentemente, surgem destas. $\mathrm{Na}$ leitura dos ACS, as demandas advindas da comunidade são mais urgentes e prioritárias. Uma situação de exacerbação da exigência de novas informações aconteceu em Tauá, em que foi incorporado o preenchimento de fichas com o modelo de cálculo de predição de risco das pessoas para diabetes. Não que esta ação seja desnecessária, mas, observou-se a necessidade de que esta nova atribuição fosse dialogada com os ACS e equilibrada com outras atividades, de forma a evitar excessos na carga de trabalho:

Nós somos muito pressionados a trabalhar. Olha, quando veio o Findrisk para nós fazermos, ninguém perguntou se nós podíamos ou se nós tínhamos tempo. Eles mandaram o Findrisk e disseram assim vocês têm até quatro de dezembro para entregar toda a população maior de vinte pesada e medida (Tauá).

A gestão precisa se aproximar dos ACS, de forma a visualizar as complexidades que eles abordam na prática, dando suporte na resolução dos problemas que envolvem múltiplas dimensões e, muitas vezes, são abordados isoladamente pelos ACS. Conforme corpus de dados deste estudo, os ACS exerciam melhor seu papel de articulador da ESF nos territórios, quanto mais a equipe e a gestão municipal de saúde criaram espaços de diálogo com estes, em um apontamento para o caminho da gestão participativa. Essa perspectiva de cogestão tem potencial de criar espaços compartilhados de poder e todos os trabalhadores envolvidos no processo de trabalho podem participar, aprender, decidir e ter maior compromisso com o processo e os resultados, possibilitando maneiras mais efetivas de lidar com a competividade, complexidade e trabalho em equipe. Sabese que essa perspectiva inovadora em relação à lógica verticalizada que se encontra nas equipes e nos serviços de saúde ainda se constitui desafio no $\mathrm{SUS}^{28,29}$ e isso foi localizado nos achados do presente estudo.

Os resultados obtidos neste estudo remetem à possibilidade de constituição de duas Comunidades de Prática fronteiriças, no contexto da ESF, a dos ACS e a integrada por todos os profissionais da equipe. A CdP dos ACS engaja e compartilha desafios e aprendizados singulares do trabalho, caracterizado pelo contato e relacionamento mais íntimo com as famílias do território, que revelam necessidades menos percebidas, ou mesmo, invisíveis aos outros profissionais da ESF. Estas necessidades, porém, não podem ser respondidas pela CdP dos ACS isoladamente. É preciso que a potencial CdP da equipe da ESF e os gestores municipais participem efetivamente do processo. Do contrário, o que ocorre é uma transferência indevida de responsabilidades do poder público em geral para um coletivo específico de trabalhadores públicos.

As reuniões de equipe da ESF se constituem oportunidades para gerar novas negociações e novos significados, espaços institucionalizados no processo de trabalho que possibilita refletir 
sobre as práticas cotidianas, favorecendo o engajamento e, por conseguinte, a melhoria da prática e as respostas dadas às necessidades de saúde da população:

A gente participa das reuniões dentro da unidade, onde a gente traz os nossos problemas, os principais problemas da área e aqui, junto com a equipe, a gente desenvolve as ações e as medidas, para que a gente consiga resolver ou, pelo menos, amenizar o problema (Tauá).

Nós temos a nossa reunião que é para agendarmos os pacientes acamados; para a gente fazer a nossa avaliação mensal com a enfermeira: (...) saber se a gente está visitando as gestantes, saber como é que estão as vacinas das crianças, se tem alguma criança com vacina atrasada, o que podemos fazer, se tem alguma visita de puérpera com a enfermeira. Então, tudo isso é feito na nossa reunião mensal (Eusébio).

Os desafios do território e de cada particularidade dos usuários da ESF são mobilizadores para o aprendizado dos ACS. O significado se configura por meio da necessidade sentida de desenvolver conhecimentos e habilidades para responder às demandas das famílias. Se não ocorre a escuta das demandas do território trazidas pelo ACS e o planejamento coletivo das ações, o ACS se desagrega e se distancia da equipe da ESF, que atua principalmente no espaço da Unidade Básica de Saúde, enfraquecendo a potencial CdP da equipe de Saúde da Família:

Com essa médica agora, a gente já consegue conciliar, a gente liga e diz: estou passando aqui numa visita. Tem uma criança doente aqui na casa. O que eu faço? Então, assim, a gente já tem a liberdade de dizer para ela e ela diz, encaminha aqui que eu vou olhar, que eu vou encaminhar para médica... facilita mais tanto a vida da pessoa como a da gente também (Eusébio).

Os dados da pesquisa apontam para o fortalecimento do potencial CdP, a partir da construção efetiva do vínculo entre os membros da equipe e as consequências positivas disso nos processos de trabalho da ESF.

\section{Processos de reificação criados por meio das práticas dos ACS e o compartilhamento dos repertórios de trabalho produzidos}

Em conjunto com a participação, a reificação é muito útil para descrever o envolvimento com o mundo como produtor de significados. Usa-se o conceito de reificação para se referir ao processo de dar forma à experiência, produzindo objetos que materializem essa experiência em "coisi- dade”. Qualquer comunidade de prática produz abstrações, ferramentas, histórias, termos e conceitos que reificam algo dessa prática, consolidando-a. E todo este conhecimento e acúmulo de experiências de trabalho, práticas e saberes são compartilhados na CdP. Assim, criam-se pontos de foco em torno dos quais a negociação do significado se organiza e é compartilhada ${ }^{19}$.

O repertório compartilhado compreende um conjunto de recursos (maneiras de fazer as coisas, rotinas, linguagem, ferramentas) socializados por uma comunidade, de forma a facilitar o trabalho em comum, criando engajamento na prática $^{19}$. Ao compor o repertório compartilhado desses profissionais nas práticas, os ACS exercem papel de educador, realizando ações educativas nas UBS e em outros espaços sociais da comunidade, atuando, também, como mobilizador da participação comunitária em grupos de saúde organizados pelas equipes da ESF e/ou do/ NASF:

Nossa parte é informação. Informar à comunidade como elas podem evitar acumular água, sempre limpando. É um trabalho de formiguinha (Eusébio).

A gente também está sempre participando, está contribuindo e através da nossa vivência diária, a gente também participa dos grupos com alguma orientação, com alguma fala da vivência da gente (Tauá).

Com a participação em uma comunidade de prática e a busca conjunta pelo desenvolvimento de um projeto comum, são criados repertórios (rotinas, protocolos etc.) que expressam o significado da negociação entre os pares de CdP. As ferramentas para desenvolvimento das práticas são desde as legitimadas pelo governo, como fichas, fardamento, crachá de identificação e prontuários eletrônicos, como inovações tecnológicas que são incorporadas por iniciativa dos profissionais da ESF (dispositivos móveis para navegar na internet e para telefonia, aplicativos de comunicação):

Surgiu o Fastmedic (prontuário eletrônico), a ficha do e-SUS. Então, algum material que a gente usava antes muitas pessoas já deixaram de usar, mas aqui eu acho que a grande maioria dos agentes de saúde usa que é aquelas fichas $A$ ou ficha $B$ que tem do hipertenso, do diabético, da gestante (Fortaleza).

Um crachá pode não significar nada para outras pessoas, mas para nós, que está dentro de uma comunidade, significa muito. E até para o policial chegar e pegar nós também... porque não tem nenhuma identificação que você está trabalhando (Fortaleza). 
Além disso, o uso do diálogo e a escuta permeiam a prática desses trabalhadores e todas essas ferramentas são significativas para prática desse profissional:

Você está dentro das casas das pessoas e você quer ganhar confiança dessas pessoas e algumas pessoas tratam você como se você fizesse parte da família. Desabafam com você, contam os problemas, contam coisas, segredos daquela família. Contam coisas que, às vezes, o marido está com problema e nem a esposa sabe (Eusébio).

Os diálogos operados na prática desses profissionais na comunidade estabelecem sentidos para as vidas, interpostos por condições e determinantes para sobrevivência. Nas conversas, as pessoas exprimem sentimentos e disponibilizam vivências mais significativas para saúde ${ }^{30}$. Com gestos, escutas e conversas horizontais, a população incorpora, em maioria, as orientações terapêuticas e as recomendações para prevenção e promoção da saúde. Emerge uma potencialidade do vínculo com a comunidade, tornando-se atributo significativo para as relações vivenciadas ${ }^{31}$.

O agir com base em valores solidários amplia a capacidade dos ACS de perceberem as necessidades de saúde invisíveis aos serviços e realizarem o cuidado que ultrapassa a oferta de ações programáticas, investindo no que é significativo para eles. Este achado também foi verificado em outro estudo ${ }^{32}$. A vivência na comunidade, como ator permanente, e a função de ser o "elo" da equipe de saúde com a comunidade parece muito incorporada à identidade deste coletivo de profissionais, e pode ser resultado da negociação de significados, própria das CdP.

Quanto aos limites do estudo, reconhece-se que para estudar a constituição de CdP, o desenho preferencial seria a etnografia. Entretanto, a pesquisa qualitativa realizada foi abrangente e revelou achados sobre dimensões presentes na prática dos ACS que se repetiram nos grupos focais e nas entrevistas com ACS dos quatro municípios, indicando a robustez dos achados.

\section{Considerações Finais}

O referencial teórico e metodológico da CdP se mostrou interessante para analisar as práticas desses profissionais, em aspectos cognitivos e subjetivos, bem como em reflexões explícitas e tácitas. Observou-se que quanto maior o envolvimento desses profissionais no processo de pactuação de um projeto em comum de atuação e na negociação de significados (engajamento), mais se potencializou a construção de novos sentidos e novas formas de participação na prática, compreendida tanto como um fazer em um contexto histórico e social, quanto como campo de construção de identidade.

Cada ato de participação ou reificação refletiu a mútua constituição entre os ACS individual e coletivamente. Práticas, linguagens, artefatos e visões de mundo refletem as relações sociais. Eles se envolveram uns com os outros, bem como com os demais participantes da equipe ESF, quando estes últimos incluem no trabalho a interlocução com os ACS. As práticas implicam uma forma de ser "ACS", formando, nessa trajetória, uma identidade que está em permanente construção, e é algo com que constantemente negociam e lidam como pessoas e profissionais.

Este trabalho aponta para importância da CdP dos ACS na ESF como um todo, facilitando o acesso da população assistida à atenção primária à saúde, em especial dos grupos mais vulneráveis, como idosos, pessoas em condição social de vulnerabilidade, acamados, crianças, gestantes, hipertensos e diabéticos. Além dessas funções normativas, este estudo contribui para explicitar, à luz da Teoria CdP, outros papéis e significados do ser ACS, os de articulador de serviços, educador social e mobilizador da participação comunitária.

O presente estudo demonstra a participação ativa e efetiva do ACS, nos processos de trabalho da ESF, sendo consequência do adentramento no território e da aproximação empática com o usuário, trazendo capilaridade para as ações e fortalecimento da ESF e do próprio Sistema Único de Saúde. 


\section{Colaboradores}

RCA Nepomuceno participou da pesquisa, análise dos dados, redação do artigo e revisão final. ICHC Barreto delineou o estudo, participou da análise dos dados, redação do artigo e revisão final. AC Frota, KG Ribeiro, AEL Ellery, FA Loiola e LOM Andrade contribuíram com a escrita do artigo e a revisão final.

\section{Financiamento}

Programa Políticas Públicas e Modelos de Atenção e Gestão de Saúde (PMA) - Vice-Presidência de Pesquisa e Coleções Biológicas (VPPCB) da Fiocruz, de 2016-2021.

\section{Agradecimentos}

A Coordenação da Rede PMA, nas pessoas de Isabela Soares Santos, Roberta Goldstein, Rosane Marques de Sousa e Isabella Koster. A Vice-Presidência de Pesquisa e Coleções Biológicas (VPPCB) da Fiocruz. As Secretarias Municipais de Saúde de Fortaleza, Eusébio, Cruz e Tauá - Ceará por todo apoio a pesquisa.

\section{Referências}

1. Brasil. Ministério da Saúde (MS). Lei no 10.507 , de 10 de julho de 2002. Cria a profissão de Agente Comunitário de Saúde e dá outras providências. Diário Oficial da União 2002; 10 jul.

2. Svitone EC, Garfield R, Vasconcelos MI, Araujo Craveiro V. Primary health care lessons from the northeast of Brazil: the Agentes de Saúde Program. Rev Panam Salud Publica 2000; 7(5):293-302.

3. Giovanella L, Mendonça MHM. Atenção Primária à Saúde. In: Giovanella L, Escorel S, Lobato LVC, Noronha JC, Carvalho AI, organizadores. Politicas e Sistema de Saúde no Brasil. Rio de Janeiro: Editora Fiocruz; 2008. p. 575-625.

4. Andrade LOM, Barreto ICHC, Paula JB. Promoção da Saúde: aspectos históricos e conceituais. In: Rouquayrol MZ, Gurgel M, organizadores. Epidemiologia e Saúde. Rio de Janeiro: Medsi Editora; 2018.

5. Ceará. Fundação Oswaldo Cruz (Fiocruz). Campo de práticas e acesso ao cuidado na Estratégia Saúde da Família no Ceará. Relatório de Pesquisa. Fortaleza: Fiocruz; 2018.

6. Nogueira ML. Expressões da precarização no trabalho do agente comunitário de saúde: burocratização e estranhamento do trabalho. Saude Soc 2019; 28(3):309323.

7. Baralhas M, Pereira MAO. Concepções dos agentes comunitários de saúde sobre suas práticas assistenciais. Physis 2011;21(1):31-46.

8. Binda J, Bianco MF, Sousa EM. O trabalho dos agentes comunitários de saúde em evidência: uma análise com foco na atividade. Saude Soc 2013; 22(2):389-402.

9. Simas PRP, Pinto ICM. Trabalho em saúde: retrato dos agentes comunitários de saúde da região Nordeste do Brasil. Cien Saúde Colet 2014; 22(6):1865-1876.

10. Lima TF. Exposição à violência comunitária durante o trabalho e seus efeitos na prática profissional na estratégia saúde da família: um estudo de corte-transversal no município de São Paulo [dissertação]. São Paulo: Universidade de São Paulo; 2017.

11. Almeida JF, Peres MFT, Fonseca TL. O território e as implicações da violência urbana no processo de trabalho de agentes comunitários de saúde em uma unidade básica. Saúde Soc 2019; 28(1):207-221.

12. Costa MC, Silva EB, Jahn AC, Resta DG, Colom ICS, Carli R. Processo de trabalho dos agentes comunitários de saúde: possibilidades e limites. Rev Gaúcha Enferm 2012; 33(3):134-140.

13. Galavote HS, Franco TB, Lima RCD, Belizário AM. Alegrias e tristezas no cotidiano de trabalho do agente comunitário de saúde: cenários de paixões e afetamentos. Interface (Botucatu) 2013; 17(46):575-586.

14. Silva ATC, Lopes CS, Susser E, Menezes PR. Depression in Primary Care Teams in Brazil. Am J Public Health 2016; 106(11):1990-1997.

15. Brasil. Ministério da Saúde (MS). Portaria no 1.886, de 18 de dezembro de 1997. Aprova as Normas e Diretrizes do Programa de Agentes Comunitários de Saúde e do Programa de Saúde da família. Diário Oficial da União; 1997. 
16. Brasil. Ministério da Saúde (MS). Portaria nº 648, de 28 de março de 2006. Aprova a Política Nacional de Atenção Básica, estabelecendo a revisão das diretrizes e norma para a organização da Atenção Básica para o Programa Saúde da Família (PSF) e o Programa Agentes Comunitários de saúde (PACS). Diário Oficial da União; 2006.

17. Brasil. Ministério da Saúde (MS). Portaria no 2.436, de 21 de setembro de 2017. Aprova a Política Nacional de Atenção Básica, estabelecendo a revisão das diretrizes para a organização da Atenção Básica, no âmbito do Sistema Único de Saúde (SUS). Diário Oficial da União; 2017.

18. Barreto ICHC, Pessoa VM, Sousa MFA, Nuto SAS, Freitas RJF, Ribeiro KG, Vieira-Meyer APGF, Andrade LOM. Complexidade e potencialidade do trabalho dos Agentes Comunitários de Saúde no Brasil contemporâneo. Saúde Debate 2018; 42(esp. 1):114-129.

19. Wenger E. Communities of practice: learning, meaning and identity. Cambridge: University Press; 1998.

20. Creswell JW. A investigação qualitativa e projeto de pesquisa: escolhendo entre cinco abordagens. Porto Alegre: Penso; 2014.

21. Barreto ICHC. Sistema Saúde Escola. In: Barreto ICHC, Loiola FA, organizadores. Comunidades de prática e saúde: uma introdução ao tema. Campinas: Saberes; 2014.

22. Bardin L. Análise de conteúdo. São Paulo: Edições 70; 2012.

23. Minayo MCS. O desafio do conhecimento: pesquisas qualitativas em saúde. São Paulo: Hucitec; 2014.

24. Brasil. Conselho Nacional de Saúde (CNS). Resolução $\mathrm{n}^{\circ}$ 466, de 12 de dezembro de 2012. Aprova normas regulamentadoras de pesquisas envolvendo seres humanos. Diário Oficial da União 2013; $13 \mathrm{dez}$.

25. Morosini MVGC, Fonseca AF, Lima LD. Política Nacional de Atenção Básica 2017: retrocessos e riscos para o Sistema Único de Saúde. Saúde Debate 2018; 42(116):11-24.

26. Brasil. Constituição da República Federativa do Brasil de 1988. Diário Oficial da União 1988; 5 out.
27. Ellery AEL, Loiola FA, Pontes RJS. Community of practice as a collective way of learning and development of practices and knowledge of the family health strategy: a theoretical study. Rev Bras Promoç Saúde 2012; 25(Supl. 2):104-112.

28. Brasil. Ministério da Saúde (MS). Secretaria de Gestão do Trabalho e da Educação na Saúde. Departamento de Gestão da Educação na Saúde. Curso de Formação de facilitadores de educação permanente em práticas de saúde: unidade de aprendizagem-análise do contexto da gestão e das práticas de saúde. Brasília: MS, Fiocruz; 2005.

29. Penedo RM, Gonçalo CS, Quelus DP. Gestão compartilhada: percepções de profissionais no contexto de Saúde da Família. Interface (Botucatu) 2019; 23:e170451.

30. Pinto AGA, Palacio MAV, Lobo AC, Jorge MSB. Vínculos subjetivos do agente comunitário de saúde no território da estratégia saúde da família. Trab Educ Saúde 2017; 15(3):789-802.

31. Costa EM, Ferreira DLA. Percepções e motivações de agentes comunitários de saúde sobre o processo de trabalho em Teresina, Piauí. Trab Educ Saúde 2011; 9(3):461-478.

32. Bezerra YRN, Feitosa MZS. A afetividade do agente comunitário de saúde no território: um estudo de mapa afetivos. Cien Saúde Colet 2018; 23(3):813-822.

Artigo apresentado em 03/08/2020

Aprovado em 22/02/2021

Versão final apresentada em 24/02/2021

Editores-chefes: Romeu Gomes, Antônio Augusto Moura da Silva 